\title{
THE NERVOUS SYSTEM OF THYSANURA.
}

\author{
William A. Hilton. \\ (Department of Zoology, Pomona College, Claremont, California).
}

The central ganglia of representative genera, Campodea, Evalljapax, Lepisma and Machilis were examined.

The first important papers dealing with any of these genera were those of Grassi 1885 and 1888. In both of these, brief discussions of the nervous system are given, but no clear picture of the complete nervous system. Probably the most copied figure of the nervous system of any thysanuran is the one of Oudemans, 1887. In this, a drawing of the complete nervous system of Machilis is given which could hardly be improved upon, but the position of the optic lobes, brain and other cephalic parts are not shown in the relations we find them within the body of the animal. In this figure there is a representation of the fine medial nerve. Another paper by Grassi in 1888 shows the general form of the nervous system of Campodea and Japax and a number of details are clearly given. Bottger, 1910, on Lepisma saccharina L. gives a very complete account of the brain and shows it to be very nearly as complex as that of other insects.

Campodea undoubtedly has the most primitive, or at least, the simplest nervous system of any of these insects. The brain is provided with antennal nerves well towards the forward end. The first ventral ganglion is nearly under the brain, then there follow three large thoracic ganglia and seven small abdominal ganglia with the last one a little larger than the rest. This corresponds to Grassi's figure, but this one gives greater detail. It was drawn from gross dissection. No frontal ganglion is shown as one was not clearly recognized in section or dissection. (Figure 1).

Japax or Evalljapax in this case, differs quite a little from Campodea in appearance, the brain is of different shape, and as it is also without eyes, the forward antennal nerves are the most marked. The ventral ganglia are a little more oval, branches are more prominent and there is one more abdominal ganglion. The last abdominal as in Campodea, is a little larger 
than the rest. The drawing is from a fresh, completely removed central nervous system. (Figure 2).
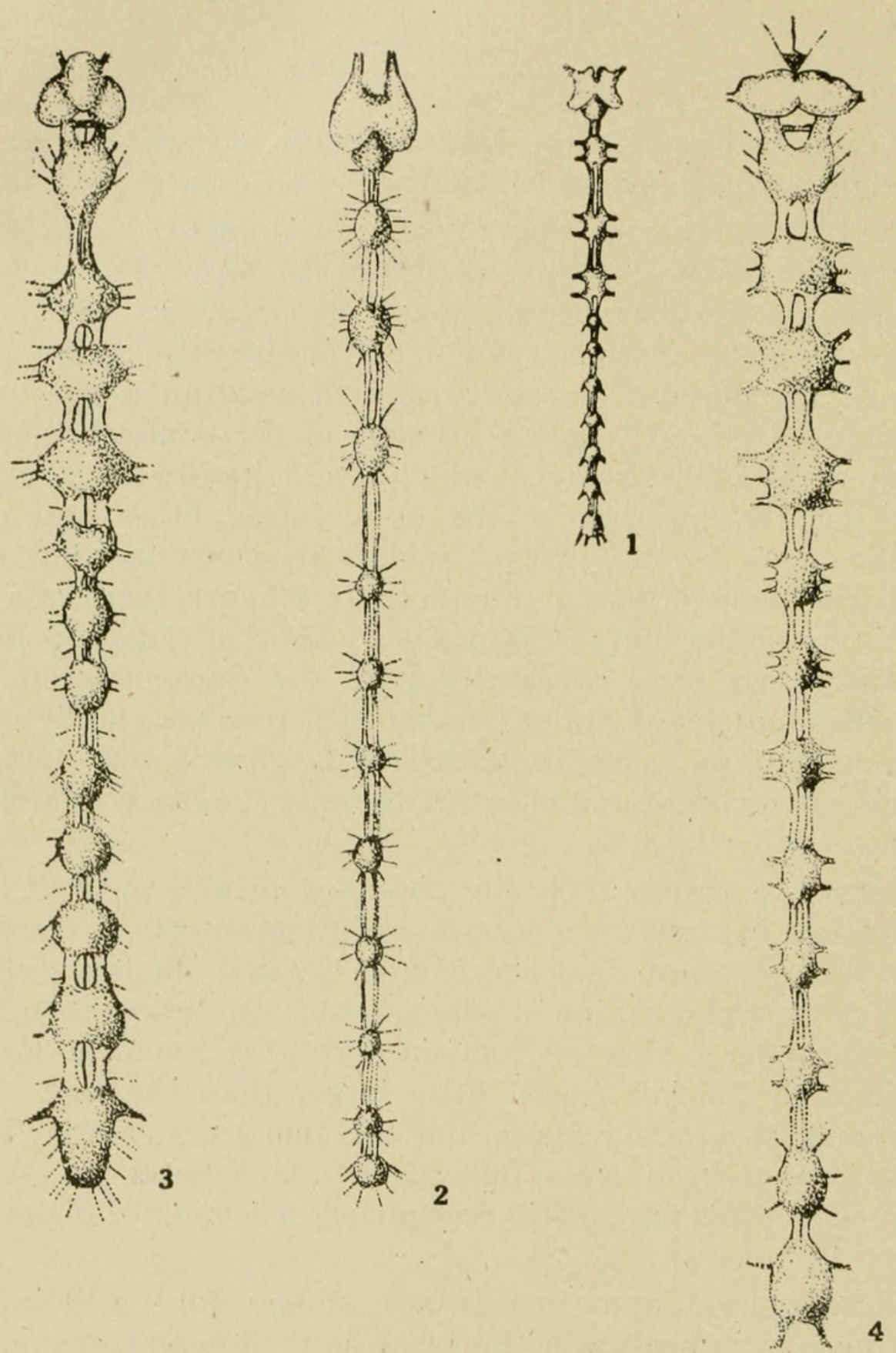

Fig. 1. Central nervous system of Campodea from above. $\times 10$.

Fig. 2. Central nervous system of Evalljapax from above. $\times 10$.

Fig. 3. Central nervous system of Machilis from above. $\times 10$.

Fig. 4. Central nervous system of Lepisma from above. $\times 10$.

Machilis has a more complicated brain, partly because of the eye_connections; it also has a general transverse direction, as 
shown in the figure and has quite a little depth. The frontal ganglion is not shown in the figure. The first ventral ganglion is large, so are the three thoracic ganglia. There are eight abdominal ganglia differing somewhat in size and somewhat from Oudemans figure. The median ventral nerve was found much as figured by Oudemans. Perhaps the most marked feature was in the backward extension of the optic lobe region because of the position of the eyes. The figure does not agree with Oudemans, largely because the brain is shown in its natural position as it is found in the head. (Figure 3).

Lepisma resembles Machilis very closely, but because of the more lateral and cephalic eyes the brain is more transverse when viewed from above. The frontal ganglion is shown in the figure. (Figure 4).

\section{TRACHEAL DISTRIBUTION.}

Trachea can be best studied by removing the ganglia and mounting while still fresh in glycerine. The air in the tracheal tubes remains for a few minutes and the distribution of the trachea may be seen. I found the tracheal distribution much as in the larva of another species. In general, the brain seems supplied by three main trachea on each side. The subesophageal ganglion by two main branches on each side, each ventral ganglion below this with one on each side, but the last ganglion with two branches at least, one of which often has some association with the branch of the next to the last ventral ganglion. Two branches seems to be the usual number for the last ganglion. (Figure 7-16).

It was very difficult to study trachea in the small Campodea because it was hard to remove the ganglia in the first place, and second because the trachea remained visible only for a short time. The lower smaller ganglia were each supplied with a single pair of branches, but the supply to the larger cephalic ganglia seemed to be by two sets of main lateral trachea from above and below, each set giving off branches as shown in the figure. The abdominal ganglia are supplied more simply. In none of the centers was there the branching of the tracheoles to the degree found in Evalljapax. 

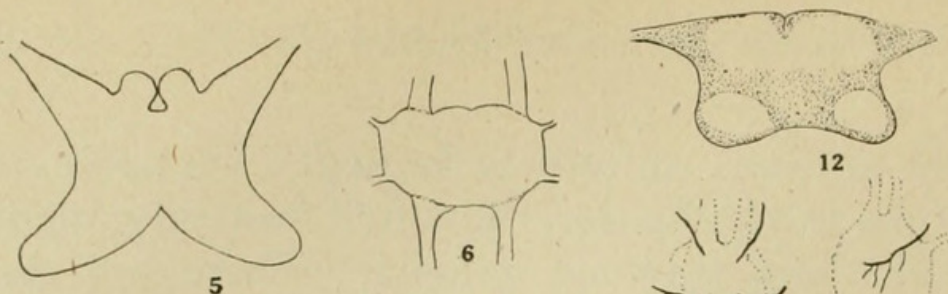

12

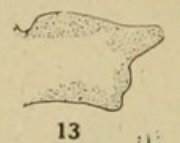

13
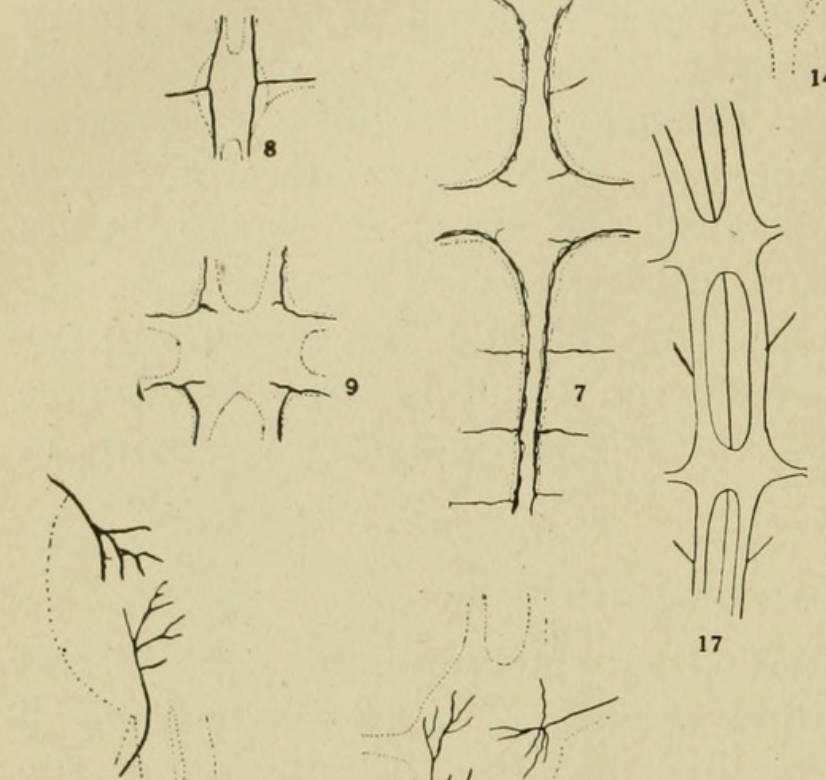

14
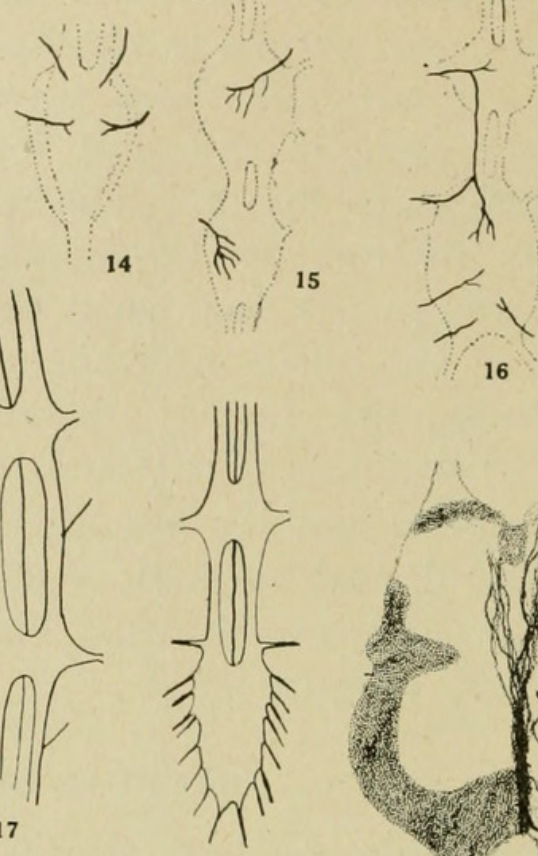

18
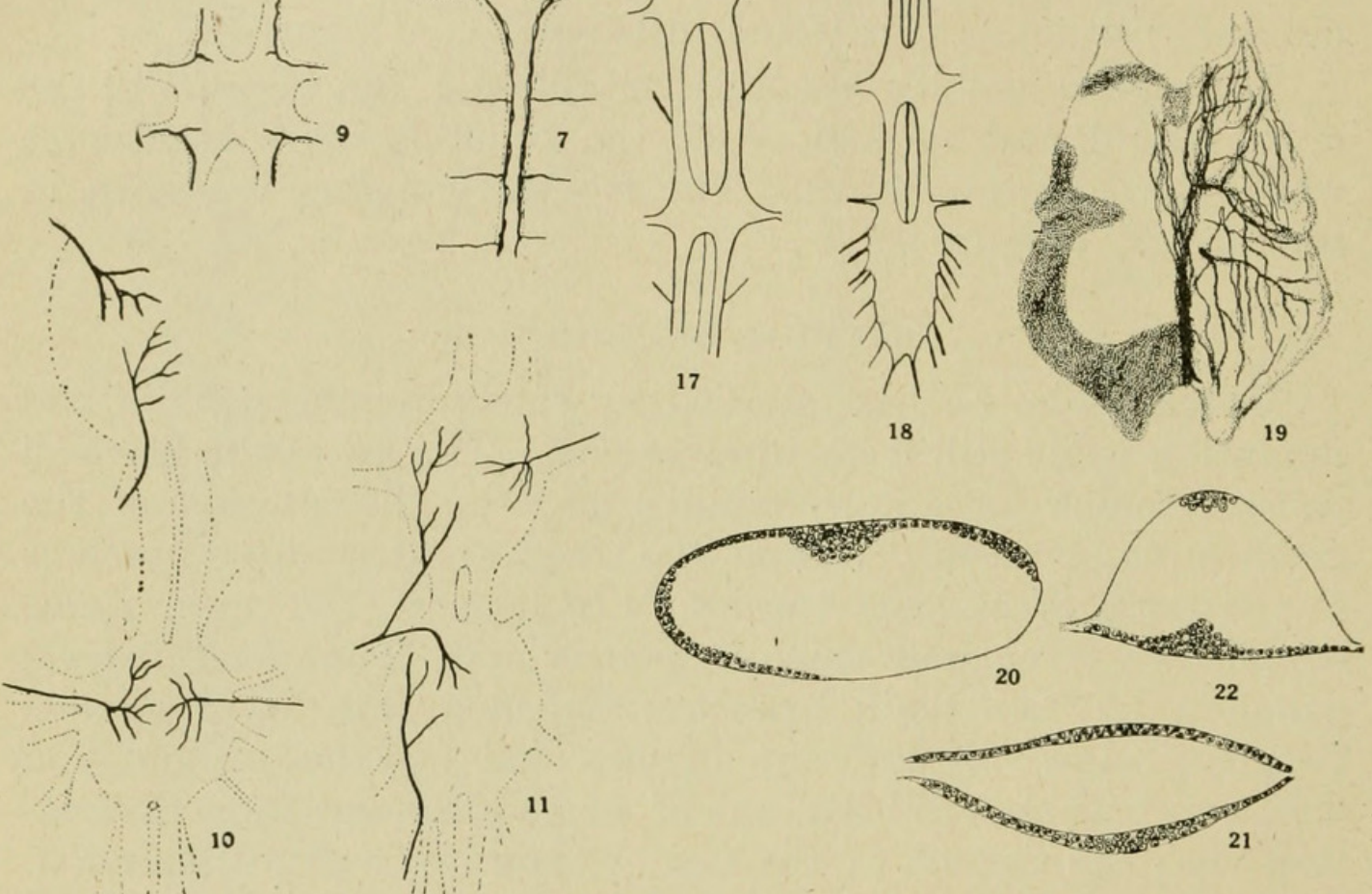

10

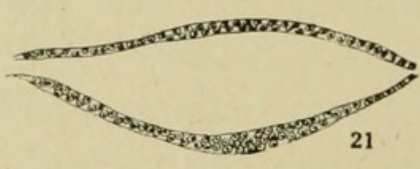

Fig. 5. Brain of Campodea from above. $\times 75$.

Fig. 6. Thoracic ganglion of Campodea from above. $\times 75$.

Fig. 7. Region of last two thoracic ganglia above and some of the abdominal ganglia in the lower part of the figure, from Campodea, showing the lateral tracheal tubes. $\times 75$.

Fig. 8. One of the abdominal ganglia of Campodea showing tracheal tubes. $\times 75$.

Fig. 9. One of the thoracic ganglia of Campodea showing tracheal tubes. $\times 75$.

Fig. 10. Tracheal distribution in the subesophageal and first thoracic ganglion of Evalljapax. $\times 50$.

Fig. 11. Tracheal distribution in the last two ganglia of Evalljapax. $\times 50$.

Fig. 12. Brain of Lepisma showing where the deeper masses of cells are as seen from a methylene-blue preparation. $\times 20$.

Fig. 13. Part of the brain of Lepisma from below showing areas of most abundant cells. $\times 20$.

Fig. 14. Subesophageal ganglion of Lepisma showing distribution of trachea.

Fig. 15. Third thoracic and first abdominal ganglia of Lepisma showing tracheal distribution. $\times 20$.

Fig. 16. Last two abdominal ganglia of Lepisma with tracheal distribution. $\times 20$.

Figs. 17 and 18. Abdominal ganglia of Machilis, showing medial nerve. $\times 22$.

Fig. 19. Brain of Evalljapax from above showing distribution of thickest masses of cells on the left side and the distribution of tracheal vessels on the right side. $\times 50$.

Figs. 20 and 21 . Supra- and subesophageal ganglia of evalljapax as shown in longitudinal section. $\times 50$. 


\section{GENERAL CHARACTER OF THE BRAIN.}

One of the chief differences between the brains of Campodea and Evalljapax as compared with Lepisma and Machilis is due to the lack of eyes in the first two. There are numerous differences between the brains of the first two genera. The shape of the brain of Campodea is given as it appears when viewed from above in Figure 5. Longitudinal and cross sections through the brain show the ventral parts largely without cells. (Figures 23-26).

The cephalic and mid-dorsal regions are not so well supplied as the lateral dorsal and caudal regions; the caudal lateral region of the brain has the largest mass of cells. Many fibers run from the brain, from or to, forward, median or lateral parts down the connectives to the subesophageal ganglion and farther. There are also numerous small bundles which connect all parts. In the latero-caudal region there are central masses of denser fibers. Three well-marked masses at least may be seen on each side near the dorso-lateral region, Fig. 23. These may represent the areas which in other species help form the mushroom bodies. The brain of Evalljapax is shown from above in Fig. 19. On the right side is shown the position of the tracheal tubes of that side and on the other the position of the larger cell areas as shown in the methylene blue preparation. The shape of the ganglion is quite different from that of Campodea, as the drawing indicates. There are cells on the dorsal side of the brain, but they are few compared to the other great areas indicated in the drawing. In section the brain seemed simpler in structure than that of Campodea, but this in part may have been the fault of the preparation. As in Campodea, the ventral regions of the brain are without cells. No clear indication of mushroom bodies was seen, and the connections between different parts of the brain and the connectives and subesophageal ganglion seemed less marked.

Machilis and Lepisma also differ from each other to a marked degree in brain structure and arrangement. The general distribution of cells above and below is shown in two figures, 12 and 13, which were stained in methylen blue. In an adult there seem to be not as many cells in proportion to the general area of fibers as in some of the other genera. The middle line both above and below is largely without cells as shown in Fig. 32, 


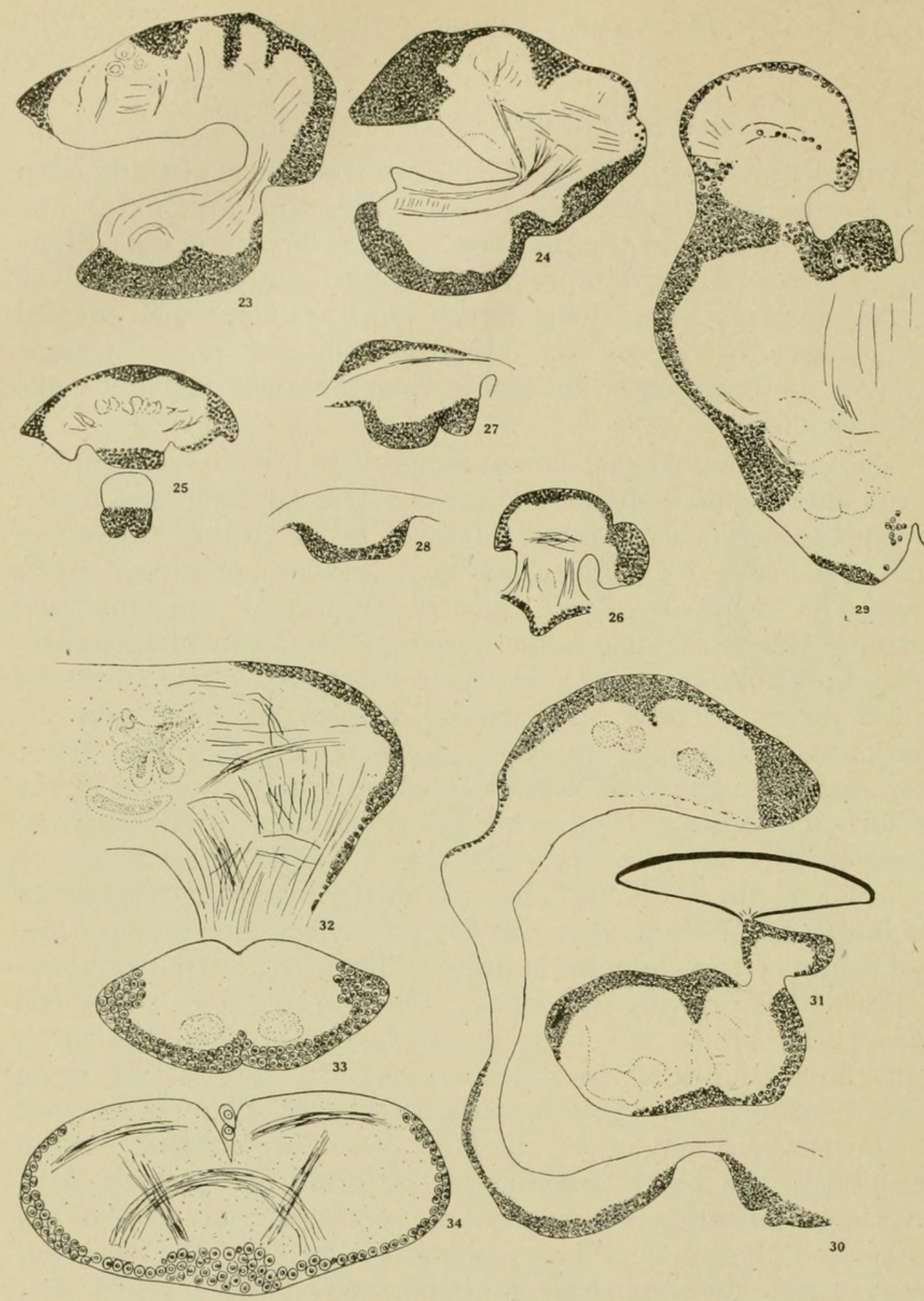

Fig. 22. Cross section through the first thoracic ganglion of Evalljapax. $\times 50$. Figs. 23 and 24. Longitudinal sections through the brain and ventral ganglion of Campodea. The cephalic end is to the right and the brain is above. Figs. 25 and 26 . Cross sections through the brain and first ventral ganglion of Campodea taken at different levels. $\times 150$.

Fig. 27. Longitudinal section through the first thoracic ganglion of Campodea, the dorsal side is above, the cephalic end at the left. $\times 150$.

Fig. 28. Longitudinal section through the second thoracic ganglion of Campodea, a the dorsal side is up. $\times 150$.

Fig. 29. Longitudinal section through the brain of Machilis. Only one-half is

shown. The optic lobe region is at the top of the figure. $\times 150$.

Fig. 30. Longitudinal section through the brain and two ventral ganglia of Machilis. $\times 150$. 
which is nearly a cross-section through the brain of an adult. In this a much more complicated structure of fibers and fibrils is presented than in any of the others so far compared. The stalks and roots of the mushroom-bodies are shown in Fig. 32, also the so-called central body. The arrangement of the fibrillar material of the mushroom seems to have a different arrangement and development than in Lepisma saccharina studied by Bottger, 1910. In his descriptions and figures an anterior and posterior division of the cap of the fibrous material or "Traube," is given but in the species studied at this time the "Traube" has a different position and is not clearly made up of more than one main lobe on each side. Each of these main lobes as shown in the figure has five secondary lobes instead of four shown by Bottger. In the region of these masses of fibrous material of the mushroom-bodies there are a number of irregular fibrous bundles which may represent other parts of this structure. On the whole, there is a fairly close resemblance to the brains studied by Bottger and differences may be due to the fact that this is not the species which he studied, but our most common local species whose exact identity has not yet been reported to me by special students of this group.

One of the first differences between the brains of Machilis and Lepisma is shown because of the different position of the eyes. The eyes of Machilis are connected with the caudal end and this dorso-caudal region forces the parts of the brain usually found here, farther forward. This is not an unusual condition among the brains of invertebrate animals, in some amphipod Crustaca as compared with nearly related isopods there is a similar shifting. In general, the posterior lobe region of the brain of segmented animals seems to represent its highest center, but shiftings such as just mentioned may often change the usual arrangements.

The second marked difference between Machilis and Lepisma at least in all specimens studied, both small and large, was in the

Fig. 31. Longitudinal section through the edge of the brain of Machilis, the section is through the eye above and to the right. The cephalic end is towards the left. $\times 150$.

Fig. 32. Cross section through the brain of Lepisma, only the right half is shown. $\times 150$.

Figs. 33 and 34 . Cross sections through two levels of the first thoracic ganglion of Lepisma. The dorsal side is up. $\times 150$. 
way of a complete lack of anything which might strictly be called mushroom-bodies in Machilis. There are however groups of fibers in the proper region of the brain in specimens of all sizes, but these are hardly more marked than in Campodea. The usual distribution of cells was found in this genus. Some indication of the complex but usual arrangement of fibers in the optic lobe region is shown in the Figures. Association, projection and commissural fibers are easily demonstrated. (Figs. 29-31).

In all the brains examined, cells of the usual and well-known types for insect brains were clearly seen. Especially was this the case with the representatives of Lepisma and Machilis. In these also there were more differences between cells. In all, nerve cells were held in place and otherwise supported by neuroglia cells and neuroglia nets. In all, the fibrils within the central portions of the ganglia formed intricate tangles with the possibility of almost unlimited connections between parts. In the smaller and simpler species few well separated definite tracts were found, fewer than in Lepisma and Machilis. This is in part due to the fact that the cells, fibers and fibrils are not so large, but there may be other reasons.

The ventral ganglia in the different species differ greatly in complexity. They seem to be the simplest in Campodea and the most complex in Lepisma. In all, the more abundant cells as is usual, are ventrally placed and the dorsal cells are usually limited to the sides and to a small group in the mid-dorsal line.

If we consider the brain from its three main pairs of nerves or three main regions on each side to consist of three lateral segments, then we must consider the subesophageal ganglion from its nerves and lobings to consist of at least two segments and very possibly more. The first thoracic ganglion in Machilis and Campodea are evidently composed of two segments as shown in the figures. The cell arrangement and fibrous bands were found to be most complex in Lepisma. A few figures are shown of ventral ganglia of several of the species (Figs. $22,27,28,33$ and 34) and a more detailed examination of the first thoracic ganglion of Lepisma, is given below.

Beginning at the cephalic end we find the two masses of the connectives distinct for a short distance, then cells are located ventrally and laterally, being thickest on the mid-ventral line. 
The cells are from one to three layers thick. The fibers in the middle line gradually form into a thick mass of commissural strands. There are also a number of diagonal fibers shown in the plane of the cross section. Farther down a second commissure makes its appearance as a narrow area crossed by coarse fibers. This crosses the center of the ganglion. Farther along a marked, much arched commissure occupies a short distance. The second commissure mentioned is quite extensive but not very thick. More dorsal arched fibers show farther along, these cross to some degree and come from lateral ventral cells, in part at least. In about the central part of the ganglion the other commissures and arched fibers have about disappeared and two small central masses of commissural fibers are evident and two ventral bundles of longitudinal fibers and marked crossings from the ventral to the dorsal side are seen. Farther along the two median commissures give place to one median arched commissure, while many branches are seen at various angles. This arched band disappears and another one comes in contributed to by marked masses of lateral cells. A few dorsal cells send their fibers straight into the ganglion from above. Farther down a more dorsal arched commissure comes in. Later there are two ventral straight bands of fibers and then a single median band reaching from side to side, then very soon the ganglion divides into the two ventral connectives. Cells on the ventral and lateral sides are seen at all levels. A few dorsal cells are seen near the central regions of the ganglion.

In the second thoracic ganglion a similar condition was noted, at least nine commissures were counted.

\section{ABDOMINAL GANGLIA.}

A general summary of the structure of abdominal ganglia of Lepisma will give an idea of their complexity:

1. Cells chiefly ventral are found in from one to two layers. The lateral ventral groups have three cell layers. There are a few mid-dorsal cells of various sizes.

2 . There are in each ganglion a large number of commissures, both straight and arched, ventral and dorsal.

3. Fibers cross dorso-ventrally and caudally.

4. Fibers run short distances to nearby cell groups. 
5. Cells of various sizes send fibers into the mass of the ganglion.

6. The longitudinal fibers to the connectives may be found in every part, but they are not always evident because of the many fine fibrils from various regions all woven in with them.

\section{SOME GENERAL CONCLUSIONS.}

The nervous systems of the four genera studied show some similarities but many differences. The general position and number of the ganglia is quite similar. Campodea, the least specialized in most respects, has one less ventral ganglion. The general shape of the four brains are quite different, even those without eyes are not alike and those with eyes have them so differently connected with the brain that the whole arrangement of the nervous system at this point is altered. Nerve cells differed chiefly in size and minor arrangements. The largest animals had the largest nerve cells. The general course of fibers and fibrils could be traced but special tracts were not traced very far. The general areas of mushroom bodies were determined for all. Only in Lepisma were these structures well developed, in Machilis and to a less degree in Campodea condensations of fibrils were taken to indicate them.

The general distribution of tracheal vessels is as follows: The brain has three main branches on each side, the subesophageal ganglion two branches from each side, the thoracic and abdominal ganglia as a rule have one branch each on a side and the last abdominal ganglion has usually two branches on each side. The brain of Campodea was not easily removed, so that the condition there was not so clearly made out, but the appearance so far as could be told was as stated for the rest. The thoracic and abdominal ganglia, however, have a distribution which is not like the rest. Possibly the long lateral trachea on either side with its branches to the ganglia may represent a more primitive if not an absolutely different condition. For this and other reasons I' am inclined to think of Campodea separated from the other genera by a wide gulf. Japax seems separated from the rest by the next widest gulf.

The segregation of fibrils in clumps means a closer union in some places than others; this probably means: 1. Fibrils are closely massed that go in the same direction. 2. In some 
places groups are closely correlated because of this relation to each other.

Nuclei are distinct from the fibers and fibrils; they are nutritive centers. The cell bodies also are important in metabolism, but they are not important enough centers for the mingling of many fibers. The individual fibers from cells are less important in the relationship of parts than the groups and masses of fibers and fibrils from many cells in conveying impulses. Association of fibrils seems more important outside of cells than in them. Why should not lateral as well as terminal contacts be important in conveying impulses? The fibrils are carried out in fibers, but the fibrils break away and are distributed in complex ways. It seems that an impulse may flow through ganglia like floods of water through a swamp. The impulses follow the lines of least resistance, if the bundle is large the direction is more definite, if small, of less importance. The nervous system of invertebrates might be compared to the heart and circulation of insects; it, like the heart, receives and passes on, but the distribution is not definite until there is a more perfect insulation. Insulation may be accomplished in several ways: (1) Bundles of fibers protect the central strands with a similar destination from loss to the surrounding parts; (2) The fibers in some cases remain distinct from each other, or the fibers are large and the inner fibrils are protected; (3) Neuroglia cells and neuroglia nets may help a little; (4) In vertebrates the more perfect insulation by means of myalin seems the most efficient protection.

\section{SPECIAL REFERENCES.}

Bottger, O. 1910. Das Gehirn eines niederen Insektes (Lepisma saccharina L.) Jen. Zeit. f. Naturw. Bd. XLVI.

GrassI, B. 1885. I progenitori degli Insetti e Miriapodi. L'Japax e la Campodea. Dagli Atti dell' Accadema Gioenia di Scienze Naturali in Catania. Ser. 3, Vol. XIX.

. 1885. Contribuzione allo studio dell Anatomia del genere Machilis. Lett. all ac. nella tornata. Mem. III. lincei. Roma. Oudemans, J. T. 1887. Bijdrage tot de kennis der Thysanura en Collembola.
Amsterdam. 


\section{$2 \mathrm{BHL}$ Biodiversity Heritage Library}

Hilton, W A. 1917. "The Nervous System of Thysanura." Annals of the Entomological Society of America 10, 303-313.

https://doi.org/10.1093/aesa/10.4.303.

View This Item Online: $\underline{\text { https://www.biodiversitylibrary.org/item/43648 }}$

DOI: https://doi.org/10.1093/aesa/10.4.303

Permalink: https://www.biodiversitylibrary.org/partpdf/193667.

\section{Holding Institution}

Smithsonian Libraries

\section{Sponsored by}

Smithsonian

\section{Copyright \& Reuse}

Copyright Status: NOT_IN_COPYRIGHT

This document was created from content at the Biodiversity Heritage Library, the world's largest open access digital library for biodiversity literature and archives. Visit BHL at https://www.biodiversitylibrary.org. 